\title{
Consumer Willingness to Purchase Impatiens walleriana Alternatives
}

\author{
Kristin L. Getter ${ }^{1,3}$ and Bridget K. Behe ${ }^{2}$ \\ Department of Horticulture, Michigan State University, A288 Plant and Soil \\ Sciences Building, East Lansing, MI 48824
}

Additional index words. bedding impatiens, impatiens downy mildew, Plasmopara obducens, purchasing alternatives, willingness to buy

\begin{abstract}
The objectives of this study were to survey Midwest consumers to assess their willingness to buy alternatives to Impatiens walleriana given the confirmed presence of Impatiens downy mildew (IDM; Plasmopara obducens) in Michigan landscapes in 2012. An Internet survey queried consumers from four states (Illinois, Indiana, Michigan, and Ohio) and questions consisted of likelihood to buy, purchasing characteristics considered, impatiens purchases in 2012, and demographic questions. Roughly 500 participants per state responded and almost three-fourths $(\mathbf{7 3 . 8 \%})$ of respondents said they planted impatiens in their landscape in 2012 . Of the $16.4 \%$ who said their plants did not look healthy at the end of the growing season, $69.3 \%$ self-identified the plant as having IDM symptoms. Purchasing characteristics that had the highest mean scores were bloom period, flower color, and longevity, whereas the lowest mean scores were for compact shape with no spindly growth, fragrance, and locally grown. Three impatiens alternative species were acceptable alternatives (scored a positive utility in the conjoint analysis) for shade-tolerant species. Begonia semperflorens was the most preferred followed by Browallia speciosa and then Impatiens hawkeri. Solenostemon scutellarioides was the least preferred. Three impatiens alternative species also scored a positive utility in the conjoint analysis and would serve well for partial shade-tolerant species. Heliotropium arborescens was the most preferred followed by Salvia splendens and then Lobelia erinus. Hypoestes phyllostachya and Iresine herbstii were preferred least as impatiens alternatives. The attribute with the highest relative importance was species for both conjoint analyses, whereas the price attribute was the least important.
\end{abstract}

Impatiens walleriana (bedding impatiens) is a colorful shade-tolerant annual that is widely used in the landscape and in hanging baskets. This species flowers in shade during most summer months (June to August) and is among the more affordable color investments for the home and commercial landscapes in Michigan. However, it is frequently used in the same landscape beds year after year as a result of perceived lack of alternatives for other colorful shade-tolerant plants.

Impatiens downy mildew (Plasmopara obducens) was observed widely in Michigan landscapes in 2012 (Hausbeck, 2012). The critical concern with this disease is that there are no consumer controls for it and once it is in the landscape, IDM may overwinter (Jennings, 2011). This means that consumers may become unsuccessful in planting impatiens in the same location in upcoming growing seasons if IDM occurred there before.

In 2010, Michigan sold more flats and hanging baskets of impatiens than any other state in the United States $(2,115,000$ and 540,000 units, respectively, greater than $\$ 17.5$ million wholesale; National Agricultural Statistics Service, 2011). In an effort to save these

\footnotetext{
Received for publication 22 July 2013. Accepted for publication 9 Sept. 2013.

${ }^{1}$ Floriculture Outreach Specialist.

${ }^{2}$ Professor.

${ }^{3}$ To whom reprint requests should be addressed; e-mail getterk@msu.edu.
}

sales, much work is being done by plant pathologists and plant breeders to find a solution for IDM. However, little work has been done on consumers' willingness to purchase alternatives, especially with the likelihood of crop failure if successive plantings of impatiens are made in the same areas. The objectives of this study were to perform a consumer survey to assess consumer willingness to buy alternative colorful shade-tolerant annual bedding plants.

\section{Materials and Methods}

Survey development and data collection. An Internet survey was developed and implemented according to Michigan State University Institutional Review Board (IRB No. $\mathrm{x} 12-1215 \mathrm{e})$ guidelines using Qualtrics software $(<\mathrm{http}$ ://www.qualtrics.com $>)$. The survey included multiple-choice (single and multiple answer) and rating (using a 1 to 5 Likert scale) question types. With the exception of screening questions, all survey questions were optional and respondents could choose to skip or choose to not answer any question.

Respondents were selected from Global Market Insite (Bellevue, WA) databases because of their panel quality and pricing. The survey was launched on 5 Mar. 2013 and was active until 13 Mar. 2013. Screening questions at the beginning of the survey ensured that the respondent resided in Illinois, Indiana, Michigan, or Ohio (500 from each state); had purchased a shade-tolerant ornamental plant within the past year; and was at least 18 years old. Subsequent questions were grouped into four categories: likelihood to buy, characteristics considered when purchasing, impatiens purchases in 2012, and demographic characteristics of the respondents.

Likelihood-to-buy questions were framed by first showing a picture of impatiens (Fig. 1) and identifying and describing the plant as a very popular flowering annual plant that thrives in full-shade conditions (less than $3 \mathrm{~h}$ direct sunlight each day), is available in a variety of colors, and is relatively inexpensive. The consumer was then asked "Suppose that all greenhouses and gardening centers are sold out of bedding impatiens this year. In the next group of questions, please answer how likely you would be to purchase an alternative to impatiens in your landscape. Each choice consists of an annual ornamental plant as it would appear in the landscape. In addition, each picture has a selling price for a 4-inch pot and the amount of time the plant is expected to look good in your landscape (longevity). For each picture, please answer how likely you would be to purchase this plant for your landscape at the given 4 -inch pot price and expected longevity." The respondent was asked to respond with a whole unit on the Likert scale of 1 (very unlikely) to 5 (very likely).

The second set of questions (purchasing characteristics) queried the importance of characteristics that consumers considered when purchasing a shade-tolerant annual bedding plant. The respondent was asked to disperse 100 points among the 13 characteristics when purchasing ornamental flowering shade-tolerant annual plants. Assigning more points to a statement meant that statement was more important to the respondent. The third block of questions (impatiens purchases in 2012) showed the impatiens image (Fig. 1) and asked the respondent if they had purchased any of these plants in 2012. If they responded in the affirmative, the survey then asked if those plants looked good (i.e., stayed green, continued flowering, etc.) throughout the entire season. If they answered in the negative, the survey continued by asking if the plants exhibited signs of leaf yellowing followed by leaf curling and then leaf dropping (Fig. 2A) or a fuzzy white coating on the underside of leaves (Fig. 2B). The fourth block of questions asked about the respondents' demographics including age, gender, ethnicity, education, and household income.

Data analysis. Conjoint analysis is a statistical method used to determine participant preferences of a hypothetical product across a given set of attributes (Kuhfeld, 2010) and was used here on the likelihood to purchase questions. Conjoint analysis defines overall preference for a particular product, in this case ornamental plants, as the sum of the part-worths (also termed utilities) for each factor level (Gaasbeck and Bouwman, 1991; Hartigan, 1975). It is a common data analysis tool used in marketing research and was developed from the main effects analysis of 
variance model (SAS Institute Inc., 1993). Conjoint studies have been used as a means to elicit consumer preferences for a wide range of ornamental products such as perennials and herbs (Behe et al., 2013), Christmas trees (Behe et al., 2005b), landscapes (Behe et al., 2005a), plant containers (Hall et al., 2010), mixed flowering annual containers (Mason et al., 2008), and native plants (Zagaden et al., 2008).

Four attributes (longevity, price, species of shade-tolerant impatiens alternatives, and species of partial shade impatiens alternatives) with three or six levels were used (Table 1). Although all 72 combinations of attributes (two attributes with three levels and two attributes at six levels each) could have been

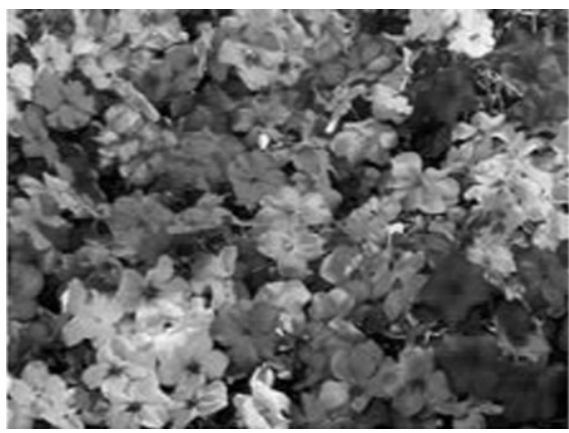

Fig. 1. The picture of impatiens displayed to participants before the likelihood-to-buy (LTB) questions. The text identified and described this plant as a very popular flowering annual plant that thrives in full-shade conditions (less than $3 \mathrm{~h}$ of direct sunlight each day) that is available in a variety of colors and is relatively inexpensive.
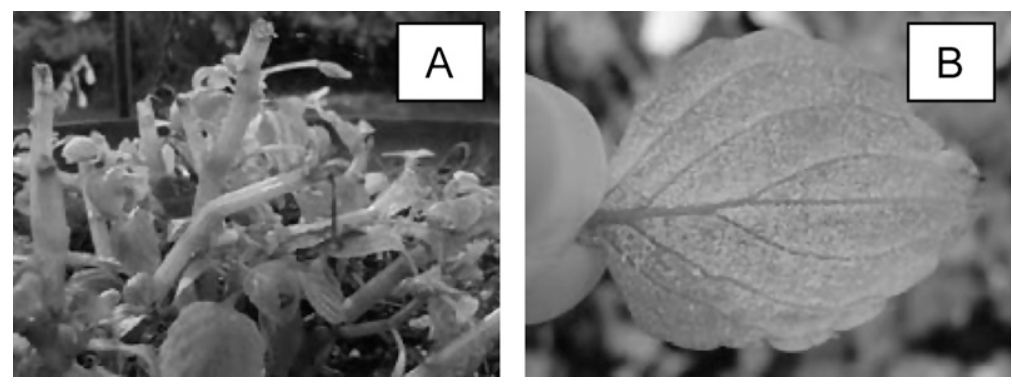

Fig. 2. Pictures shown to respondents who answered that they did purchase impatiens in 2012 and the plant did not look good all season long. These pictures accompanied the question asking if the plants exhibited signs of leaf yellowing followed by leaf curling and then leaf dropping (A) or a fuzzy white coating on the underside of leaves $(\mathbf{B})$.

presented to respondents for a full profile conjoint, to reduce respondent fatigue, a two partial factorial design was chosen to generate a list of 18 combinations of hypothetical ornamental plant products (for a total of 36 questions).

The first conjoint set queried images of ornamental shade-tolerant plants with a listed price and longevity (Fig. 3). The second conjoint was similar, except it displayed partial shade-tolerant ornamental plants with price and longevity (Fig. 4). Species chosen in this study were chosen based on suitable alternatives to Impatiens walleriana identified by the researchers and believed to be most available in a retail setting based on researchers' industry visits. Species images shown to the consumer were taken by the researchers or colleagues used with their permission. Levels for price were chosen based on 2012's market price of similar products. Longevity levels were chosen based on the local climate (3month growing season).

Conjoint analysis was conducted in SAS Version 9.3 (SAS Institute, Cary, NC) using PROC TRANSREG. Means of coefficients and relative importance across respondents were analyzed in PROC GLM for significant differences between attributes and clusters (identified below using factor analysis). For the question regarding purchasing characteristics, the numerical means of 100 points assigned to each characteristic were analyzed using PROC MIXED in SAS Version 9.3 (SAS Institute) and comparisons were performed using Tukey's honestly significant test with $P=0.05$ as a maximum value of significance.

Factor analysis (PROC FACTOR; SAS Version 9.3) was also used on this question.
Table 1. Attributes and levels used in two conjoint analyses for likelihood to purchase questions

\begin{tabular}{|c|c|}
\hline Attributes & Levels \\
\hline \multicolumn{2}{|l|}{ Shade-tolerant ornamentals } \\
\hline Species & $\begin{array}{l}\text { Begonia rex hybrids (Rex begonia), Begonia semperflorens (wax begonia), Browallia speciosa (Browallia), } \\
\text { Fuchsia } \times \text { hybrid (Fuschia), Impatiens hawkeri (New Guinea impatiens), Solenostemon scutellarioides (Coleus) }\end{array}$ \\
\hline Longevity & 1 month, 2 months, 3 months \\
\hline Price for a 4-inch pot & $\$ 1.99, \$ 2.49, \$ 2.99$ \\
\hline \multicolumn{2}{|c|}{ Partial shade-tolerant ornamentals } \\
\hline Species & $\begin{array}{l}\text { Heliotropium arborescens (Heliotrope), Hypoestes phyllostachya (polka-dot plant), Iresine herbstii (Iresine), } \\
\text { Lobelia erinus (Lobelia), Salvia splendens (Salvia), Torenia fournieri (wishbone flower) }\end{array}$ \\
\hline Longevity & 1 month, 2 months, 3 months \\
\hline Price for a 4-inch pot & $\$ 1.99, \$ 2.49, \$ 2.99$ \\
\hline
\end{tabular}

Factor analysis is a statistical method that seeks to reduce a set of large observable variables into a smaller number of latent factors (UCLA Statistical Consulting Group, 2013). These factors are then used to explain most of the observed variance. The number of factors was identified based on eigenvalues and scree plots. Participants were then grouped into clusters based on their standardized scoring coefficients generated from the factor analysis using the principal component analysis extraction method with a Varimax rotation, which ensured that the resulting factors were not correlated (UCLA Statistical Consulting Group, 2013).

\section{Results}

Demographics. There were 2002 respondents who met the criteria for purchasing a shade-tolerant ornamental in the past year, $\approx 500$ participants per state (Table 2). The mean respondent age was 52.3 years, of which two-thirds were female and most lived in a suburban setting, and most were white. In addition, most had at least some college and nearly $40 \%$ earned $\$ 40,000$ to $\$ 79,999$ in household income for 2012. Because all demographic measures were statistically similar among the four states, data collected were pooled.

Problems with impatiens in 2012. Almost three-fourths $(73.8 \%)$ of respondents said they planted impatiens in their landscape in 2012 (Table 3). Of these, most $(78.2 \%)$ said the plants looked good at the end of the growing season. However, $16.4 \%$ of them said their plants did not look healthy at the end of 2012's growing season. Of those whose impatiens did not look healthy at the season's end, $69.3 \%$ self-identified the plant as having IDM symptoms.

Important characteristics when purchasing plants. Bloom period, flower color, and longevity had the highest mean scores for respondents' 100 -point dispersals to characteristics (Table 4). The lowest mean scores were compact shape with no spindly growth, fragrance, and locally grown. Factor analysis of these attributes produced two factors or dimensions (Table 5). Factor 1 was defined as "pre-purchase considerations" because it had the highest standardized scoring coefficients for absence of discolored or damaged foliage, absence of dropped or wilted leaves, evidence of new growth, and compact shape with no spindly growth. Factor 2 was termed 


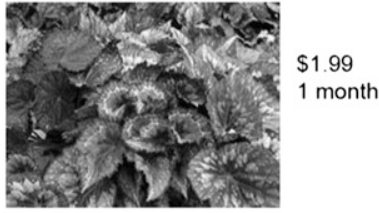

A

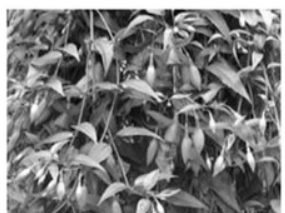

D

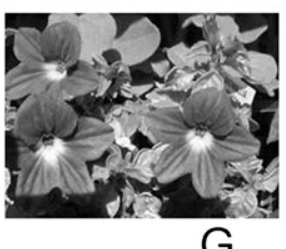

$\$ 1.99$

1 month

G
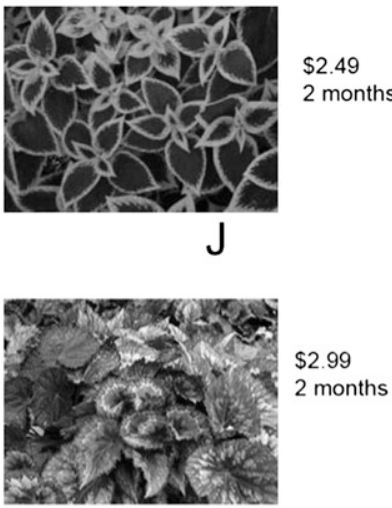

M

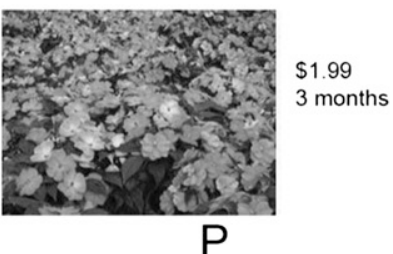

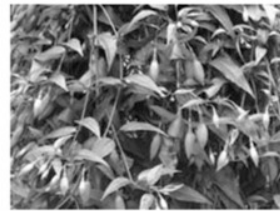

$\$ 2.99$ 3 months

B
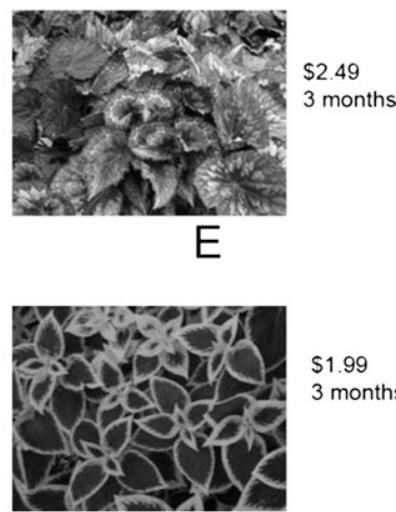

$\$ 1.99$

3 months

$\mathrm{H}$

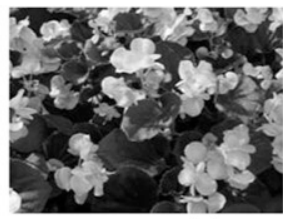

$\$ 1.99$

2 months
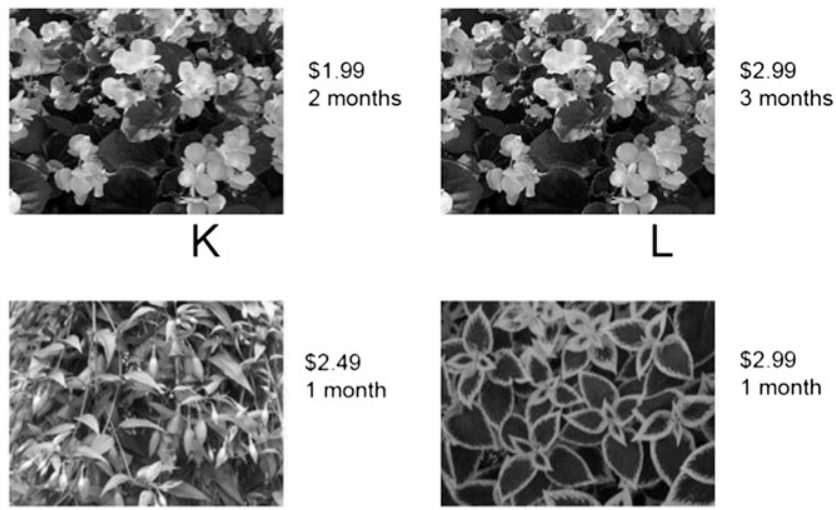

$N$

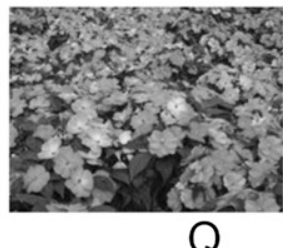

$\$ 2.49$

2 months

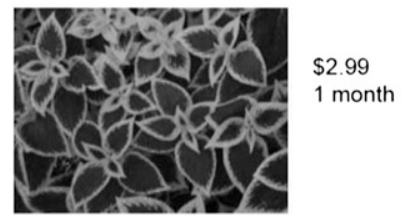

$\mathrm{O}$

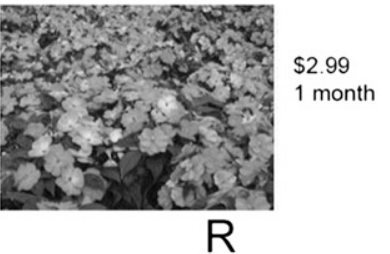

Fig. 3. First conjoint set. Respondents were asked to rate each picture on a scale of 1 (very unlikely) to 5 (very likely) in terms of how likely they would be to purchase this plant that thrives in the shade in a 4-inch pot at the given price and longevity.

"post-purchase considerations" because it had high coefficients for bloom period and length of time the plant survives in my yard/garden.

Participants were then clustered into four groups based on each of their individual factor scores and there were few differences in demographics between clusters (data not shown). Cluster 1 comprised $23.5 \%$ of the sample and was defined as those participants whose pre- and post-purchase consideration factors were less than 0 (neither initial plant health nor length of survival or bloom time in their yard was important). Cluster 2 comprised $27.4 \%$ of the sample and was defined as those participants whose pre-purchase consideration factor score was less than 0 but whose post-purchase consideration factor score was greater than 0 (initial plant health was less important than how long the plant will bloom and survive in their yard). Cluster 3 comprised the smallest percentage of the sample $(18.7 \%)$ and was defined as those participants whose pre- and post-purchase consideration factors were greater than 0 (both initial plant health and the length of time the plant bloomed and survived were important). Cluster 4 , the largest segment at $30.3 \%$ of the sample, was defined as those participants whose pre-purchase consideration factor scores were greater than 0 and whose post-purchase consideration scores were less than 0 (initial plant health much more important than the length of bloom time or survival in the garden). Both Clusters 3 and 4 (participants who valued initial plant health) highlight the importance of quality merchandising displays. Nearly $70 \%$ of buying decisions are unplanned; thus, developing attractive point-ofpurchase (POP) displays is essential to stimulating sales (Stahlberg and Maila, 2010). Research verifies that in-store displays have the capacity to capture attention and increase sales (East et al., 2003; Nördfalt, 2011). Our findings are consistent with prior studies and 

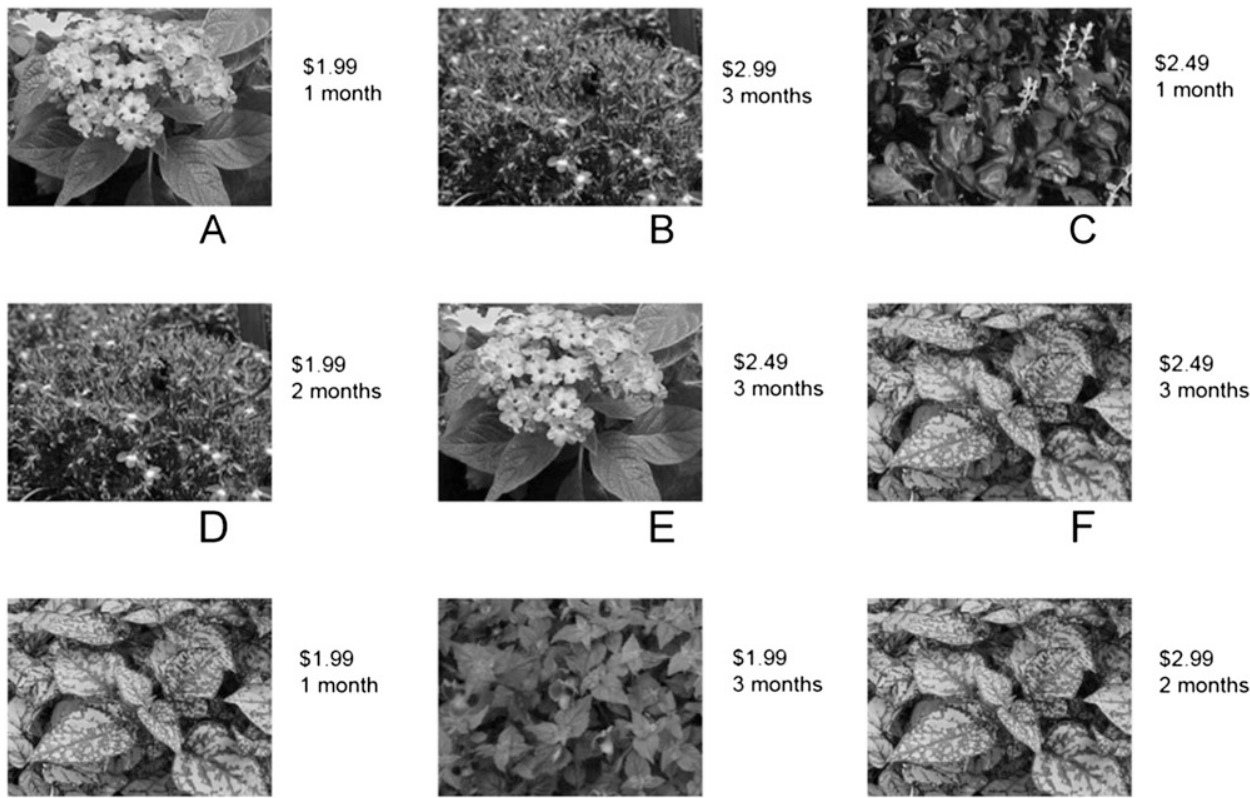

1 month

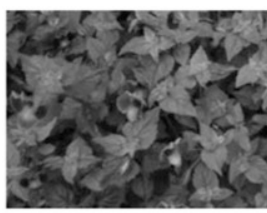

$\$ 1.99$

3 months

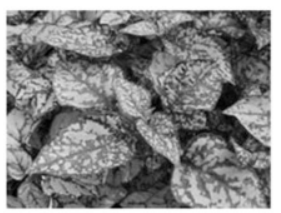

$\$ 2.99$

2 months

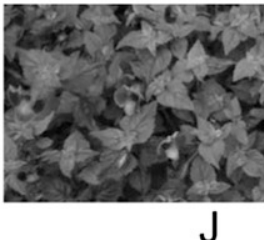

$\$ 2.49$ 2 months

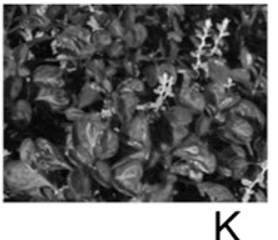

$\$ 1.99$

2 months

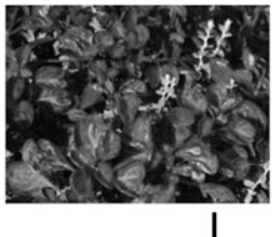

$\$ 2.99$

3 months

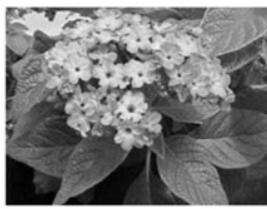

$\$ 2.99$

2 months
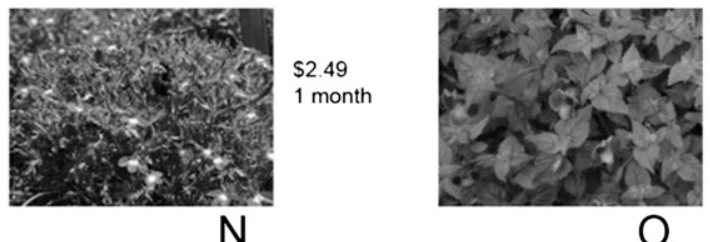

$\$ 2.99$

1 month

M

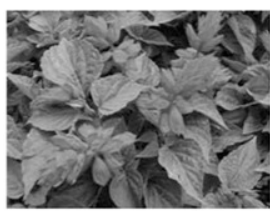

$\$ 1.99$

3 months
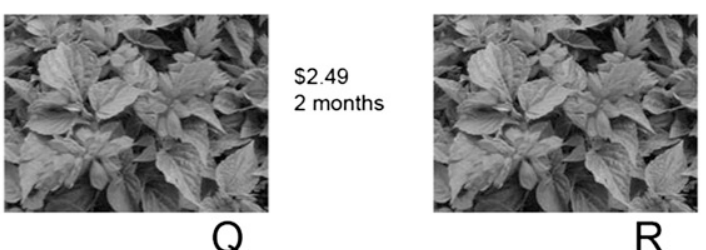

$\$ 2.99$

$\$ 2.49$

2 months

$\mathrm{P}$

Q

$\mathrm{R}$

Fig. 4. Second conjoint set. Respondents were asked to rate each picture on a scale of 1 (very unlikely) to 5 (very likely) in terms of how likely they would be to purchase this plant that thrives in the partial shade in a 4-inch pot at the given price and longevity.

underscore the importance of quality merchandise at the POP.

Conjoint analysis. Part-worth utility estimates for both conjoint question sets showed that customers preferred plants that last longer in the landscape ( 3 months preferred over 1-month survival) and lower prices were preferred to higher prices (Table 6). These results are consistent in findings and showed consumer logic (e.g. lower prices and longer bloom period preferred). In addition, low price preference is consistent with other conjoint analyses (Behe et al., 2013; Mason et al., 2008).

For the first conjoint question set (shadetolerant species), three impatiens alternative species scored a positive utility. Begonia semperflorens was the most preferred followed by Browallia speciosa and then Impatiens hawkeri. Solenostemon scutellarioides was preferred least. For the second conjoint question set (partial shade-tolerant species), three impatiens alternative species also scored a positive utility. Heliotropium arborescens was the most preferred followed by Salvia splendens and then Lobelia erinus. Hypoestes phyllostachya and Iresine herbstii were preferred least as impatiens alternatives.

The attribute with the highest relative importance was species for both conjoint analyses (Table 6). Longevity was the next most important attribute, whereas the price attribute was the least important for both conjoint analyses.

For both conjoint analyses, part-worth utility estimates by cluster showed that participants who valued post-purchase considerations higher (Clusters 2 and 3 ) rated a 1-month plant longevity much more negatively than the two other clusters (Table 7) and the reverse was true for 3-month longevity. In addition, part-worth utility estimates for price were the same for each cluster. For the full-shade conjoint analysis, Cluster 1 preferred Begonia rex hybrids the least over other cluster memberships and preferred Browallia speciosa more than other cluster 
Table 2. Demographical characteristics of participants in an Internet survey that assessed consumer willingness to buy alternative colorful shade-tolerant annual bedding plants.

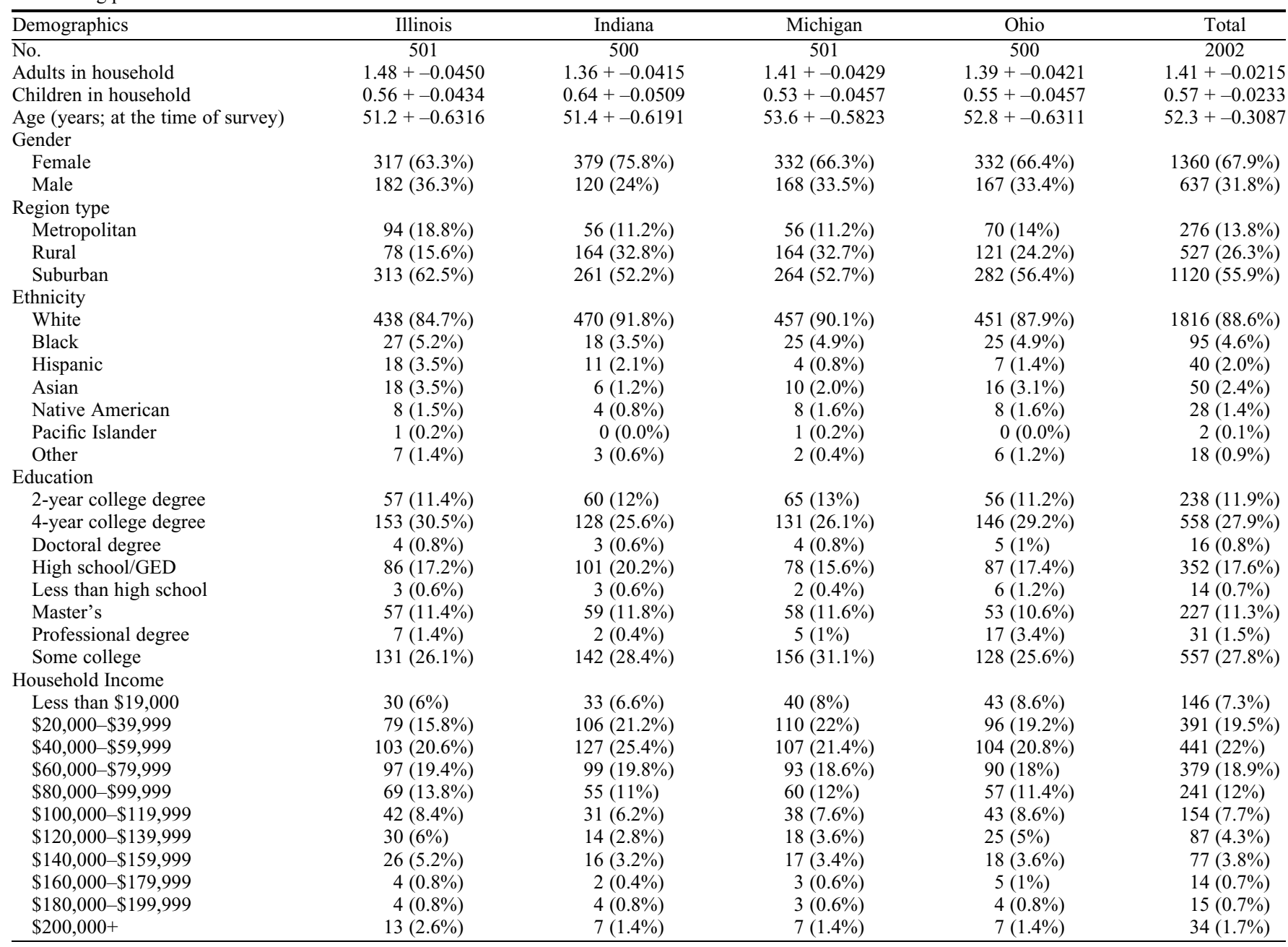

Table 3. Consumer self-reporting of planting and health of impatiens (excluding New Guinea impatiens) in their landscape at the end of the 2012 growing season.

\begin{tabular}{lc}
\hline Question & Mean counts (\%) \\
\hline Did plant impatiens last year & $1470(73.8 \%)$ \\
Did impatiens look good at end of season? \\
Do not remember & $79(5.4 \%)$ \\
Yes & $1146(78.2 \%)$ \\
No & $241(16.4 \%)$ \\
Impatiens had IDM & $167(69.3 \%)$ \\
$\quad$ symptoms & \\
Did not plant impatiens & $521(26.2 \%)$ \\
last year &
\end{tabular}

${ }^{\mathrm{z}}$ Percent is of those that planted impatiens last year. ${ }^{\mathrm{y}}$ Percent is of those that said their impatiens did not look good at the end of the season.

IDM = Impatiens downy mildew.

memberships. The partial shade conjoint analysis demonstrated that participants in Cluster 1 preferred Heliotropium arborescens and Lobelia erinus more so than other clusters and Iresine herbstii less so than other clusters. Relative importance showed that overall Cluster 1 participants valued longevity less so than other clusters and species more than other clusters (Table 8), whereas price was equal across clusters for both conjoint analyses.

Table 4. Mean (SE) points assigned (out of 100 points) to the following characteristics when purchasing ornamental flowering shade-tolerant annual plants. $^{\mathrm{z}}$

\begin{tabular}{lc}
\hline Characteristic & Mean point assignment (SE) \\
\hline Absence of discolored or damaged foliage & $6.9(0.22) \mathrm{C}$ \\
Absence of dropped or wilted leaves & $5.4(0.15) \mathrm{DE}$ \\
Bloom period & $17.6(0.35) \mathrm{A}$ \\
Compact shape with no spindly growth & $3.9(0.14) \mathrm{F}$ \\
Evidence of new growth & $5.8(0.16) \mathrm{CDE}$ \\
Foliage characteristics including leaf shape, summer and fall color & $6(0.17) \mathrm{CD}$ \\
Flower color & $15.2(0.28) \mathrm{B}$ \\
Flower size & $6.4(0.17) \mathrm{C}$ \\
Fragrance & $3.8(0.14) \mathrm{F}$ \\
Length of time the plant survives in my yard/garden & $14.9(0.29) \mathrm{B}$ \\
Locally grown & $2.6(0.13) \mathrm{G}$ \\
Overall plant size & $5.5(0.15) \mathrm{DE}$ \\
Unusual flower color & $5.2(0.17) \mathrm{E}$ \\
Other $^{\mathrm{x}}$ & $1(0.14) \mathrm{H}$ \\
\hline
\end{tabular}

${ }^{2}$ Uppercase letters denote differences in columns by mean separation using Tukey's honestly significant difference $(P \leq 0.05){ }^{\mathrm{y}}$

${ }^{y}$ For mean separation, data was transformed with an arcsine square root transformation to achieve normality and stabilize variances.

${ }^{x}$ Other text included (number of times mentioned in parentheses): attract hummingirds and butterflies (five); amount of care needed (six); cost (37); drought-tolerant (five); hardiness (four); pest, disease, deer, or rabbit-resistant (six); and size at maturity (two).

\section{Summary and Conclusions}

Nearly $75 \%$ of Midwestern consumers who planted annuals in the shade planted impatiens in the season before this study with $\approx 11 \%$ of this sample identifying IDM as a problem. Few demographic differences in the samples from each of the four states were minimal, indicating a relatively homogeneous sample with regard to demographic characteristics. 
Given the persistence of the disease and lack of consumer landscape controls, substitute species for impatiens should be recommended to producers, retailers, and consumers. However, which of the large palette of shade-tolerant plants should producers be recommended as most likely substitutes? Of the 12 Impatiens walleriana substitutes suggested to study participants, six emerged as most likely substitutes because they had positive part-worth utility estimates: Begonia semperflorens, Browallia speciosa, Heliotropium arborescens, Impatiens hawkeri, Lobelia erinus, and Salvia splendens. Three species that were least preferred as alternatives are lower in likelihood to be substitutes and they include Hypoestes phyllostachya, Iresine herbstii, and Solenostemon scutellarioides.

Factor analysis revealed two constructs: pre-purchase and post-purchase considerations. When asked to distribute 100 points among 14 factors, bloom period (a postpurchase attribute) flower color (a prepurchase attribute), length of time the plant survives in my yard/garden (a post-purchase attribute), and absence of discolored or damaged foliage (a pre-purchase attribute) were the top four considerations. When participants were segregated into four clusters based on their factor scores, the groups to emerge were either low/high on Factor 1 (pre-purchase) and/or Factor 2 (postpurchase). Few demographic differences were identified among the four groups, indicating they are relatively homogeneous in demographic composition. The largest group produced in the cluster analysis was $30 \%$ of the sample (Cluster 4 ) and those consumers were more focused on pre-purchase attributes than post-purchase attributes, whereas the smallest group (Cluster 3) had factor scores greater than 0 for both pre- and post-purchase attributes. Both of these clusters

Table 5. Standardized scoring coefficients of factor analysis using the principal component analysis extraction method with a Varimax rotation using two factors against 13 point assignment characteristics ("other" was left out because it resulted in a covariance matrix of zeros).

\begin{tabular}{lcc}
\hline Characteristic & $\begin{array}{c}\text { Factor 1 pre-purchase } \\
\text { considerations }\end{array}$ & $\begin{array}{c}\text { Factor 2 post-purchase } \\
\text { considerations }\end{array}$ \\
\hline Absence of discolored or damaged foliage & 0.63952 & -0.00918 \\
Absence of dropped or wilted leaves & 0.57384 & -0.08240 \\
Bloom period & -0.21622 & 0.76525 \\
Compact shape with no spindly growth & 0.29757 & -0.05037 \\
Evidence of new growth & 0.33054 & -0.20296 \\
Foliage characteristics including leaf shape, & 0.04073 & -0.10491 \\
$\quad$ summer and fall color & & \\
Flower color & -0.55476 & -0.13795 \\
Flower size & -0.26160 & -0.25453 \\
Fragrance & -0.07091 & -0.34371 \\
Length of time the plant survives & -0.16055 & 0.40427 \\
$\quad$ in my yard/garden & & \\
Locally grown & 0.07978 & -0.24414 \\
Overall plant size & -0.05569 & -0.26414 \\
Unusual flower color & -0.12650 & -0.34957 \\
\hline
\end{tabular}

highlight the importance of quality merchandise at the POP.

Conjoint analysis showed that the attribute with the highest relative importance was species $(49 \%$ to $56 \%$ of the likely to buy decision) with species shown varying moderately $(-0.41$ to 0.32 and -0.25 to 0.32$)$ in part-worth utility scores. The price attribute (15\% and $13 \%$ of the likely to buy decision) was the least important and longevity was intermediate in importance $(29 \%$ and $37 \%)$ for both conjoint analyses. Thus, results from both conjoint analyses conducted here were consistent in findings, showed consumer logic (e.g. lower prices and longer bloom period preferred), and agreed with other findings regarding low price preference on other crops. There was no difference in the relative importance of price by cluster, but there were differences in the relative importance for longevity and species by cluster.

Results point to the recommendation of a relatively homogenous communication program, which emphasizes product attributes consumers considered relatively more important (bloom period, flower color, and longevity). Retailers should highlight these attributes while consumers are in the retail location because pre-purchase attributes were important to nearly half $(49 \%$, or Clusters 3 and 4) of the sample and so many purchases are made on impulse. Producers now have a better understanding of the more/less probable impatiens alternatives. They can, and should, work with retailers to communicate the presence of IDM and recommend alternative plants at the POP because so many sales can be influenced there.

IDM is likely to persist as a Midwestern landscape concern, causing growers, retailers, and consumers to adopt alternatives. The investigation reflects a limited sample to the center of the United States where the disease

Table 6. Part-worth utility estimates (SE) and relative importance (SE) for the two conjoint analyses. ${ }^{2}$

\begin{tabular}{|c|c|c|c|c|}
\hline \multirow{2}{*}{ Attribute } & \multicolumn{4}{|c|}{ Conjoint \# } \\
\hline & \multicolumn{2}{|c|}{ 1: shade-tolerant species } & \multicolumn{2}{|c|}{ 2: partial shade-tolerant species } \\
\hline Longevity & & $28.65(0.465) \mathrm{B}$ & & $37.07(0.583) \mathrm{B}$ \\
\hline 2 months & $0.01(0.006) \mathrm{E}$ & & $0.03(0.006) \mathrm{EF}$ & \\
\hline 3 months & $0.45(0.011) \mathrm{A}$ & & $0.6(0.013) \mathrm{A}$ & \\
\hline Price & & $15.09(0.235) \mathrm{C}$ & & $13.3(0.231) \mathrm{C}$ \\
\hline$\$ 1.99$ & $0.18(0.006) \mathrm{D}$ & & $0.14(0.006) \mathrm{C}$ & \\
\hline Species: shade-tolerant & & $56.26(0.541) \mathrm{A}$ & & \\
\hline Begonia rex hybrids & $-0.12(0.017) \mathrm{F}$ & & & \\
\hline Begonia semperflorens & $0.32(0.016) \mathrm{B}$ & & & \\
\hline Browallia speciosa & $0.26(0.014) \mathrm{C}$ & & & \\
\hline Fuchsia $\times$ hybrid & $-0.19(0.018) \mathrm{G}$ & & & \\
\hline Impatiens hawkeri & $0.15(0.015) \mathrm{D}$ & & & \\
\hline Solenostemon scutellarioides & $-0.41(0.017) \mathrm{H}$ & & & \\
\hline Lobelia erinus & & & $0.06(0.013) \mathrm{DE}$ & \\
\hline Salvia splendens & & & $0.11(0.014) \mathrm{CD}$ & \\
\hline Torenia fournieri & & & $-0.01(0.013) \mathrm{F}$ & \\
\hline
\end{tabular}

${ }^{\mathrm{z}}$ Uppercase letters denote differences in columns by mean separation using Tukey's honestly significant difference $(P \leq 0.05)$. 


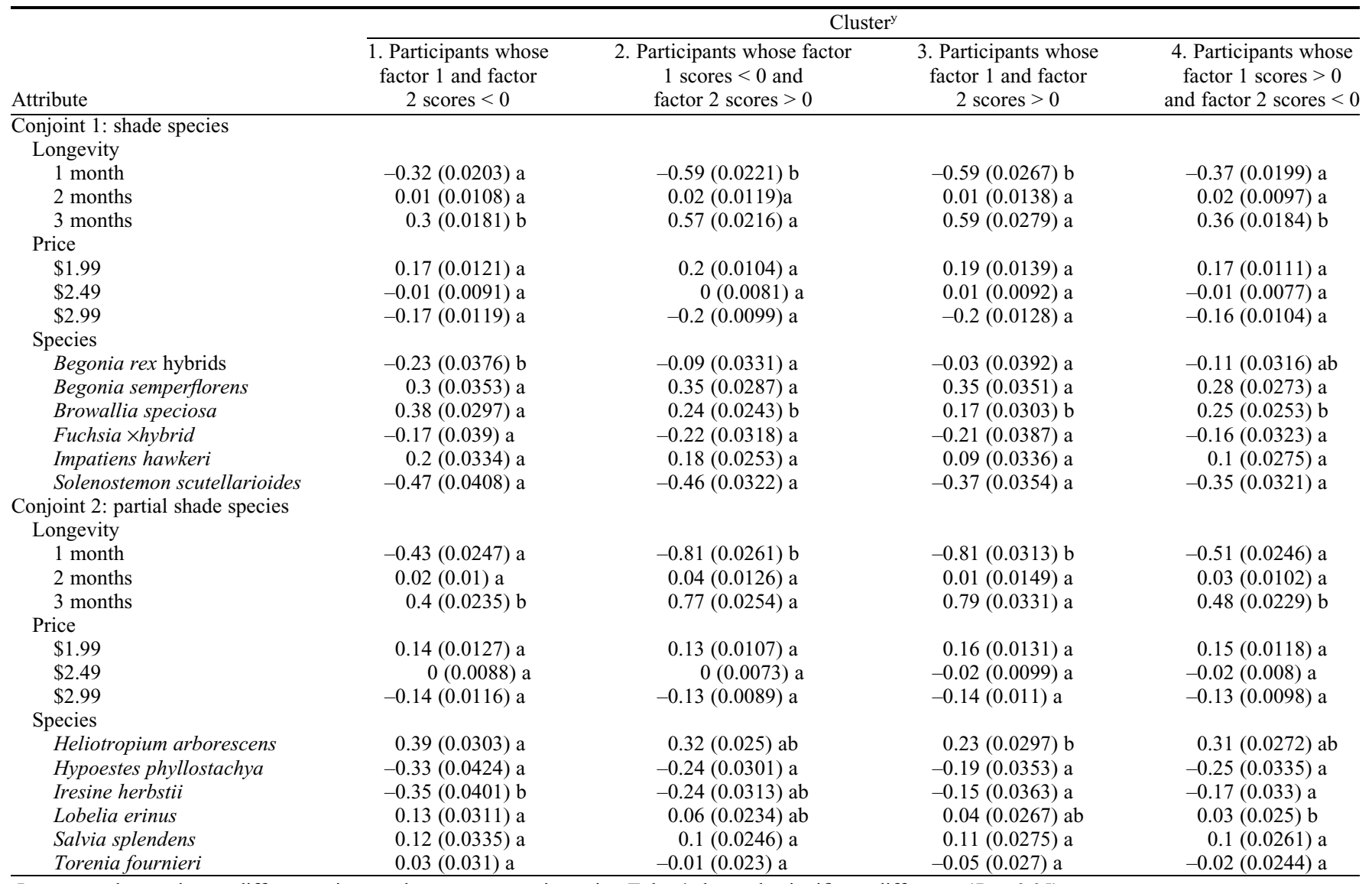

${ }^{2}$ Lowercase letters denote differences in rows by mean separation using Tukey's honestly significant difference $(P \leq 0.05)$.

${ }^{y}$ See text for definition of cluster membership. In brief, clusters were created based on participants factor scores: Cluster $1=$ suggested neither initial plant health/ length of survival nor bloom time in their yard were highly important; Cluster $2=$ initial plant health not nearly as important as how long the plant will bloom and survive in their yard; Cluster $3=$ both initial plant health and the length of time the plant bloomed and survived were very important; Cluster $4=$ initial plant health much more important than the length of bloom time or survival in the garden.

Table 8. Relative importance score (SE) by cluster for two conjoint analyses. ${ }^{z}$

\begin{tabular}{|c|c|c|c|c|}
\hline \multirow[b]{2}{*}{ Attribute } & \multicolumn{4}{|c|}{ Cluster } \\
\hline & $\begin{array}{l}\text { 1. Participants whose } \\
\text { factor } 1 \text { and factor } \\
2 \text { scores }<0\end{array}$ & $\begin{array}{l}\text { 2. Participants whose } \\
\text { factor } 1 \text { scores }<0 \text { and } \\
\text { factor } 2 \text { scores }>0\end{array}$ & $\begin{array}{l}\text { 3. Participants whose } \\
\text { factor } 1 \text { and factor } 2 \text { scores }>0\end{array}$ & $\begin{array}{l}\text { 4. Participants whose factor } 1 \\
\text { scores }>0 \text { and } \\
\text { factor } 2 \text { scores }<0\end{array}$ \\
\hline Price & $14.45(0.505) \mathrm{a}$ & $14.73(0.428) \mathrm{a}$ & $14.91(0.5233) \mathrm{a}$ & $15.95(0.4482) \mathrm{a}$ \\
\hline Species & $63.88(1.0513) \mathrm{a}$ & $51.65(1.0143) \mathrm{c}$ & $50.4(1.2819) \mathrm{c}$ & $58.16(0.9662) \mathrm{b}$ \\
\hline \multicolumn{5}{|c|}{ Conjoint 2: partial shade species } \\
\hline Species & $59.14(1.207) \mathrm{a}$ & $43.42(1.1225) \mathrm{c}$ & $40.68(1.3029) \mathrm{c}$ & $53.45(1.1073) b$ \\
\hline
\end{tabular}

${ }^{\mathrm{z}}$ Lowercase letters denote differences in rows by mean separation using Tukey's honestly significant difference $(P \leq 0.05)$.

outbreak is known. Results may be indicative of other U.S. regions, but this should be tested. Subsequent investigations may evaluate the sales of several of these alternatives to see whether they increase as sales and planting of impatiens are anticipated to decline.

\section{Literature Cited}

Behe, B.K., B.L. Campbell, C.R. Hall, H. Khachatryan, J.H. Dennis, and C. Yue. 2013. Consumer preferences for local and sustainable plant production characteristics. HortScience 48:200-208.

Behe, B.K., J. Hardy, S. Barton, J. Brooker, T. Fernandez, C. Hall, J. Hicks, R. Hinson, P.
Knight, R. McNiel, T. Page, B. Rowe, C. Safley, and R. Schutzki. 2005a. Landscape plant material, size, and design sophistication increase perceived home value. J. Env. Hort 23:127133.

Behe, B.K., R.M. Walden, M. Duck, B. Cregg, K. Kelley, and R.D. Lineberger. 2005b. Consumer preferences for and cost of production of tabletop Christmas trees. HortScience 40:409-412.

East, R., V. Eftichiadou, and M. Williamson. 2003. Research note: Point-of-purchase display and brand sales. Intl. Rev. of Retail, Distribution and Consumer Res 13:127.

Gaasbeck, A. and V. Bouwman. 1991. Conjoint analysis in market research for horticultural products. Acta Hort.: Hort. Economics and Mktg 295:121-125.
Hall, C.R., B.L. Campbell, B.K. Behe, C. Yue, R.G. Lopez, and J.H. Dennis. 2010. The appeal of biodegradable packaging to floral consumers. HortScience 45:583-591.

Hartigan, J.A. 1975. Clustering algorithms. John Wiley and Sons, New York, NY.

Hausbeck, M. 2012. Downy mildew on impatiens becomes widespread in Michigan landscapes. MSU Extension News Bulletin. 19 June 2013. <http://msue.anr.msu.edu/news/downy_ mildew_on_impatiens_becomes_widespread_ in_michigan_landscapes $>$.

Jennings, P. 2011. Control of downy mildew (Plasmopara obducens) an economically important foliar disease on Impatiens. The STC Research Foundation, Stockbridge Technology Centre, Cawood ,Selby, North Yorkshire, YO8 3TZ, 
Research paper PC 230a. 20 May 2013.<http:// www.hdc.org.uk/sites/default/files/research_ papers/PC\%20230ab\%20final\%20report.pdf>.

Kuhfeld, W.F. 2010. Marketing research methods in SAS. SAS Institute, Inc., Cary, NC.

Mason, S., T. Starman, R.D. Lineberger, and B.K. Behe. 2008. Consumer preferences for price, color harmony and care information of container gardens. HortScience 43:380-384.

National Agricultural Statistics Service. 2011. Floriculture Crops Summary 2010 Summary.
Sp Cr 6-1(11). U.S. Department of Agriculture, Washington, DC.

Nördfalt, J. 2011. Improving the attention-capturing ability of special displays with the combination effect and the design effect. J. of Retailing and Consumer Serv. 18:169-173.

SAS Institute Inc. 1993. SAS technical report R109 , conjoint analysis examples. SAS Institute Inc., Cary, NC.

Stahlberg, M. and V. Maila. 2010. Shopper marketing: How to increase purchase decisions at the point of sale. Kogan Page Limited, Philadelphia, PA.

UCLA Statistical Consulting Group. 2013. Factor analysis using SAS PROC FACTOR. 22 Apr 2013. <http://www.ats.ucla.edu/stat/sas/library/ factor_ut.htm $>$.

Zagaden, Y., B.K. Behe, and R. Gough. 2008. Consumer preferences for native plants in Montana residential landscapes and perceptions for naturalistic designs. J. Environmental Horticulture 26:109-114. 